\title{
A ação dos trabalhadores na consolidação da Assistência Social como Direito
}

ELAINE ROSSETTI BEHRING*

Resumo: O presente artigo debate os desafios da construção da política de assistência social, considerando a cultura política brasileira secular e a contra-reforma do Estado nos anos 90. Estes são elementos que vêm obstando a seguridade social no país. Na sequência o artigo analisa o papel dos trabalhadores no campo da assistência, tendo em vista a perspectiva da acessibilidade aos direitos e a necessidade de uma nova cultura institucional, ética e política, voltada para o público. Nesse sentido, coloca-se um novo perfil de trabalhadores da área. São articuladores que fortalecem a construção de uma reforma democrática do Estado, na qual se insere a assistência como política de seguridade.

Palavras-Chave: Contra-reforma do estado, seguridade social, neoliberalismo, filantropia.

Abstract: The present artícle talks about the challengers to construct the social assistance policy, considering the secular Brazilian politics culture and the counter-reform of the state on nineties. These are the elements to explain the paralysis of the social security in Brazil. On the sequence, the artícle analyse the role of workers in assistance scope, to promote the access to rights and a new institucional culture, ethics and politics, geared towards to public. Then, the article draw a new profile to workers in this area. They are articulators which strengthen the democratic reform of the State construction, where is social assistance as security policy.

Keywords: Counter-reform of the state, social security, neoliberalism, philantropy.

*Professora Adjunta do Departamento de Política Social da FSS/UERJ, Doutora em Serviço Social pela UFRJ e Ex-Presidente do CFESS (Gestão 1999/2002). E-mail: elan.rosbeh@uol.com.br 
A primeira vez que apresentei publicamente uma reflexão sobre o tema específico do papel dos trabalhadores na Assistência Social foi em 2001, em atenção a um gentil convite da Prefeitura Municipal de Belo Horizonte, para uma plenária dos trabalhadores da área, preparatória das Conferência Municipal e Nacional previstas naquele ano. Ali estavam presentes muitos assistentes sociais, mas não exclusivamente. Tratava-se de uma interlocução com trabalhadores de um município cujo governo estava (e ainda permanece) no campo democrático e popular, e que procurava trabalhar de fato na perspectiva das orientações e princípios preconizados na Lei Orgânica da Assistência Social (LOAS), o que supunha, a meu ver, uma reforma democrática do Estado, ainda que nos limites do espaço local, e a busca de um novo perfil para os trabalhadores da área.

Aquelas reflexões iniciais foram enriquecidas para e no debate em seminário ${ }^{1}$ realizado na UnB, em 2002. O evento contou basicamente com a presença de estudantes, profissionais e professores de Serviço Social.

Um outro espaço de amadurecimento tem sido a discussão no contexto da revisão curricular da FSS/UERJ, realizada em 2002, com um intenso debate sobre o perfil profissional, no caso, do assistente social. A estes movimentos, não posso deixar de acrescentar a reflexão sobre a seguridade social, com destaque para a Assistência Social, no âmbito do Conjunto CFESS/CRESS nos últimos nove anos, experiência riquíssima em sugestões e, sobretudo, conectada com os imensos desafios na área. Isto porque, dentre outros aspectos, este foi um período de resistência. O desenho constitucional da seguridade social pública foi frequentemente obstado e/ou esvaziado pelas políticas neoliberais na última década.

Estou descrevendo este percurso porque os elementos que vou sugerir neste artigo incorporam muito do que foi debatido em todas essas ocasiões. Uma prefeitura democrático-popular com a intenção de fazer diferente, de garantir direitos. As universidades preocupadas em formar ou capacitar profissionais que atuem na

\footnotetext{
Trata-se do Seminário "Assistência Social, Direito de Cidadania", coordenado pelas professoras Denise Bomtempo e Ivanete Boschetti, do DSS/UnB, realizado ao longo do mês de março, em 2002, cujo convite me propiciou mais um momento importante de interlocução para a elaboração deste artigo.
} 
perspectiva do direito e não na reiteração de condutas clientelistas e tutelares. E entidades profissionais envolvidas na luta pela implementação do conceito constitucional de seguridade.

As linhas a seguir serão marcadas por uma preocupação de fundo que esteve no centro de minhas pesquisas recentes: como assegurar uma efetiva reforma democrática do Estado brasileiro condição ideal para o desenvolvimento de uma política de assistência social em sintonia com a LOAS, a qual, por si, já é constitutiva da mesma - bastante diferente da contra-reforma regressiva da qual fomos testemunhas ou vítimas nos anos $90 .^{2} \mathrm{E}$ trazem também a aposta na possibilidade histórica e, porque não dizer, na obrigação política de governos democráticos e populares "fazerem a diferença", nesse contexto ainda adverso, mesmo que a eleição de Lula seja a demarcação de uma nova correlação de forças no Brasil. Este poderá ser um momento privilegiado para tornar a Assistência Social uma efetiva inovação original, em contraposição ao conservadorismo, parafraseando Boschetti (2001), e de realizar reformas efetivas, retomando o fio condutor do processo de redemocratização do país, rompido pela nossa segunda década perdida. Estamos vivendo hoje uma experiência democrática e popular no nível federal, o que pela primeira vez abre condições para uma verdadeira política nacional, para a superação das soluções adhoce focalizadas sempre limitadas, e para um investimento em recursos humanos capacitados para a perspectiva do direito.

\section{Assistência Social como Direito: uma reforma democrática}

A primeira questão a ser apontada parte da seguinte constatação: ainda que prevaleça uma vontade político-econômica de promover mudanças nos padrões brasileiros de sociabilidade, e

2 A idéia de que houve no Brasil uma contra-reforma do Estado, e não um conjunto de reformas supostamente modernizadoras como costumam afirmar os signatários das mudanças da era FHC, encontra-se em minha tese de doutorado intitulada $A$ Contra-Reforma do Estado no Brasil, defendida no âmbito do Programa de Pós-Graduação em Serviço Social da UFRJ. A recusa de que o ocorrido nos anos 90 foram reformas parte da constatação factual da destruição (não-criadora, conforme Tavares, 1999) engendrada pelo Plano Real, a exemplo de seus impactos no emprego, na indústria e na seguridade social. Mas há também um resgate do significado político da idéia de reforma, historicamente imbricada com mudanças redistributivas e civilizatórias, conduzidas pela social-democracia, em contraposição às estratégias revolucionárias e anticapitalistas. Portanto, qualquer mudança - mesmo que originada nas atualmente transfiguradas hostes social-democratas - não pode ser caracterizada como reforma. As dos anos 90 muito menos, considerando sua natureza regressiva e destrutiva. Cf. Behring (2002b). 
o processo coletivo de trabalho no âmbito das políticas públicas se desenvolva num ambiente que se oriente por princípios democráticos e compromissos ético-políticos com a justiça social e a democracia, este conjunto de elementos se move no Brasil numa dupla contracorrente.

Um contraposição inicial se dá em relação às manifestações do passado no presente: os espectros de que Marx nos fala em seu 18 de Brumário (1976) e que insistem em se mesclar no tempo presente, fazendo a história parecer repetir-se, mas como tragédia ou farsa. Falo de características mais duradouras e estruturais da formação social brasileira, da nossa transição conservadora para a modernidade, diga-se, da via não-clássica (Coutinho, 1989) da formação do capitalismo brasileiro e de suas instituições políticas, e do ambiente intelectual e moral a ela correspondente. Estes processos, tão bem apropriados por Caio Prado Jr. e Florestan Fernandes, dentre outros (Behring, 2002, Capítulo 2), nos deixaram de herança um país fortemente desigual, heterônomo e dependente, marcado por uma cultura política senhorial, patrímoníalista e clientelista, na qual as fronteiras entre o público e o privado se diluem num eterno conluio (Schwarz, 1977). Ou seja, uma cultura política marcadamente antidemocrática e antipública, e que atravessa o Estado e a sociedade brasileiras, do Oiapoque ao Chuí, mesmo considerando particularidades regionais. No campo do enfrentamento das expressões da questão social, essa cultura manifestou-se historicamente por ações que oscilaram entre o assistencialismo, a tutela e o favor de um lado, e a repressão de outro, diga-se, pela distância em relação à idéia de direito. O liberalismo, e seu mix com o escravismo que gerou nossa forma "à brasileira" (Fernandes, 1987; Schwarz, 1977), tratou de dar substrato ideológico e econômico à perspectiva de crescer e não dividir com os "de baixo", donde direitos de natureza redistributiva, sobretudo não-contributiva, só vieram à luz pela primeira vez com a Constituição de 1988 e ainda com critérios bastante restritos e resistências.

A segunda contraposição dá-se em relação à atualização desse drama crônico, como dizia Florestan Fernandes (1987), ou desse mito fundador da brasilidade, de que nos fala Marilena Chauí (2000). Nos anos 90 - de contra-reforma no país -, aprofundaram-se a desigualdade social e a heteronomia, diga-se, dependência e subordinação no âmbito do mercado mundial a partir do nosso passaporte passivo para a mundialização. Reiterou-se o 
conservadorismo e a condução antidemocrática das decisões significativas, a exemplo do volume inusitado de medidas provisórias ${ }^{3}$ e da balcanização do Congresso Nacional. O drama crônico brasileiro exprimiu-se, desta vez, por meio do projeto neoliberal, fundado na macroeconomia do Plano Real, conduzido por FHC, no qual as expressões da questão social foram "enfrentadas" por meio de políticas focalizadas e compensatórias, afastando-se do conceito constitucional de seguridade ou ignorando-o solenemente, como foi o caso do Plano Diretor da Reforma do Estado (MARE/1995), no qual este termo não é pronunciado uma só vez. Portanto, levar adiante uma experiência de gestão da política pública de assistência social na direção constitucional do direito universal de cidadania significou, nos anos 90, remar contra a maré, enfrentar obstáculos econômicos, políticos e culturais seculares e atuais no Estado (em todos os seus níveis) e na sociedade brasileira. Desafios que, penso, permanecem latentes apesar da vitória eleitoral da esquerda em 2002. Daí, paradoxalmente, decorre o potencial político e transformador da luta em defesa da seguridade social pública e de suas políticas setoriais: seu caráter estratégico, como expressa o importante documento do CFESS intitulado Carta de Maceió (2000).

Os recentes acontecimentos destrutivos e regressivos no país atingiram a todos - mesmo quando havia no nível local uma vontade política coletiva em outra direção. Isto porque geraram o recrudescimento da pobreza e da miséria, bem como do desemprego e da informalidade (Mattoso, 1999), aumentando, no caso da Assistência Social, a demanda por benefícios e serviços, cujo atendimento foi restrito àqueles que se enquadraram nos critérios restritos de acesso aos benefícios, programas e projetos. Tais critérios - a exemplo do VA do salário mínimo per capita para concessão do Benefício de Prestação Continuada para idosos e pessoas portadoras de deficiência- estiveram pautados pela relação com a capacidade de trabalho, num mundo em que não há trabalho para todos, e foram submetidos à lógica focalista e privatista engendrada pelo ajuste neoliberal no país, o que gerou a ausência de proteção social para grandes contingentes da população brasileira.

A contra-reforma no campo assistencial já vinha explicitada no PDRE/MARE (1995). Além de repassar essa atividade- atenção: a assistência não existia como política pública de seguridade no PDRE-

\footnotetext{
${ }^{3}$ Foram 4.982 MP's até abril de 2001, segundo levantamento do INESC (maio de 2001).
} 
MARE - aos Termos de Parceria (OSCIP) e Contratos de Gestão (OS), a "reforma" atropelou o Conselho Nacional de Assistência Social (CNAS) ao propor o credenciamento daquelas entidades privadas com fins públicos (Terceiro Setor) no Ministério da Justiça, o que "facilitaria e desburocratizaria" o processo. Nosso passado recente mostrou como as subvenções sociais para entidades credenciadas sem critérios técnicos eram a expressão dos mais puros clientelismo e patrimonialismo, e uma das críticas feitas por representantes da sociedade civil ao projeto foi exatamente a ausência de um parecer técnico sobre a entidade, pela área na qual ela pretende atuar. ${ }^{4}$

Aqui, vale sinalizar que a criação de um novo marco legal para as ONGs e organizações sem fins lucrativos - que se tornou a regulamentação das OSCIPs - era uma requisição desses segmentos, que foi viabilizada através do Programa Comunidade Solidária, mas que não incorporou o conjunto das preocupações elencadas por aqueles setores. Por outro lado, é muito ténue a diferença entre o novo marco legal do Terceiro Setor e a legislação que regulamentou as organizações sociais, o que poderá gerar tensões e distorções no futuro próximo, já que foram criadas legislações concorrentes. $\mathrm{Na}$ assistência social, foi ignorado ainda todo o movimento que rompeu com o padrão de atividade focal, pontual e assistencialista, e que a transformou em política pública e parte da seguridade social, remetendo-a à solidariedade privada, ${ }^{5} \mathrm{e}$ colocando a LOAS em situação de extrema vulnerabilidade.

Essa condição implicou perda ou restrição dos direitos constitucionais regulamentados na LOAS (1993). Segundo a detalhada pesquisa de Boschetti (2001), as inovações originais que acompanharam a incorporação da assistência social no conceito brasileiro de seguridade social pública foram seguidamente afrontadas, a partir de uma perspectiva focalista e seletiva, em nome de supostas prioridades, a começar pela instituição do já referido

\footnotetext{
4 Embora o CNAS também venha padecendo com o clientelismo, quanto à emissão dos Certificados de Entidades Beneficentes de Assistência Social (CEBAS). Esta é outra forma de transferência de responsabilidades para a esfera privada, pela via da renúncia fiscal, além das OS (transformação de instituições estatais em privadas) e OSCIPs (termo de parceria para a prestação de serviços por instituições privadas), já que dão isenção da contribuição para a Seguridade Social (CFESS, 2001). Um caso de irregularidades na concessão deste certificado e que ganhou notoriedade na imprensa foi o da Legião da Boa Vontade (LBV), sendo que após inúmeros recursos e diligências, o CNAS indeferiu a renovação desta entidade. (Cf. O Globo, 25 de novembro de 2001).

5 Sobre a apropriação da idéia de solidariedade como elemento ideológico central do ajuste neoliberal, consultar o trabalho de Gusmão (1998).
} 
Comunidade Solidária. Dessa forma, o que se viu foi a redução ou manutenção em ritmo estático do acesso aos direitos assistenciais.

Vale lembrar que a LOAS já nasceu sob o tacão do ajuste fiscal, cuja maior expressão foi a definição do corte de renda de ${ }_{4}^{1 /}$ do salário mínimo per capita de uma família inteira para um portador de deficiência ou idoso com mais de 70 anos, pertencente a esta família, fazer valer seu direito de acesso ao Benefício de Prestação Continuada (BPC). Este, por sua vez, só começou a ser implementado a partir de 1996 - três anos após a aprovação da LOAS. Já houve, portanto, naquela ocasião - quando Cardoso era Ministro da Fazenda -a definição de um critério restritivo, ao passo que um amplo universo de atores envolvidos com a assistência social, inclusive os assistentes sociais, falavam de $1 \mathrm{ou}^{1 /}{ }_{2}$ salário mínimo per capita, tendo em vista uma cobertura maior dos benefícios.

O estudo de Boschetti (2001, p. 61) mostra as tendências de redução dos atendimentos financiados via Fundo Nacional de Assistência Social (FNAS) e o caráter residual de seu alcance. Dessa forma, a lógica fiscal e segmentar sobrepôs-se à universalidade que deveria orientar a implementação da LOAS. No caso do BPC, benefício que só pode ser acessado caso não haja na família nenhuma pessoa beneficiária da Previdência Social ou do segurodesemprego, instituiu-se na LOAS que seria direito de idosos com 70 anos ou mais, idade que seria diminuída em 48 meses para 65 anos. No entanto, por Medida Provisória, depois transformada na Lei 9.720 , de 30 de novembro de 1998, a idade foi fixada em 67 anos, restringindo o acesso ao direito.

Segundo Boschetti (2001, p. 63), em 2000, o BPC cobria apenas $15,82 \%$ dos idosos e $24,4 \%$ dos portadores de deficiência, considerando o universo estimado pela PNAD/95, que trabalha com o corte de V2 salário mínimo per capita. Os benefícios eventuais (auxílio funeral e natalidade, além de outros voltados para situações emergenciais) sequer foram regulamentados, seja por proposta do governo, seja pelo Conselho Nacional de Assistência Social (CNAS). O estudo mostra a queda dos atendimentos nos serviços de ação continuada (creches, PPD e idosos), especialmente para pessoas portadoras de deficiência (PPD), para as quais os atendimentos caíram de 9\%, em 1989, para 4,9\%, em 1999 (p. 64), bem como a redução dos projetos de combate à pobreza. O Programa de Erradicação do Trabalho Infantil (PETI) foi o que teve o crescimento mais considerável, mas, ainda assim, atingia apenas $10,62 \%$ do 
universo possível, em 1999 (p. 67). Considerando a rigidez da desigualdade e dos números da pobreza no Brasil, amplamente sinalizados pelo último censo, Boschetti conclui:"(...) a atuação do poder público federal na normalização das ações e, sobretudo, na liberação de recursos, é absolutamente tímida ante a drástica situação de miséria e desigualdade imperante no Brasil" (p. 67). Daí decorre sua caracterização de que os direitos assistenciais convivem numa dialética entre a originalidade, no campo dos princípios inéditos previstos em lei, e o conservadorismo - resistência à implementação do marco legal, por parte do governo e sua base social de apoio.

O que cabe sublinhar aqui é que houve restrição do que já era restrito no âmbito da assistência social, a partir das lógicas fiscal e da já referida capacidade para o trabalho ${ }^{6}$ assumidas pelo governo federal. Estas também se combinam à responsabilização da enaltecida - e concebida de forma indiferenciada - sociedade civil (Duriguetto, 2003), para a qual são transferidas as ações no campo assistencial, com o que se cria uma situação na qual o que seria direito termina por perder-se no poder discricionário e opaco dos critérios privados, configurando o retrocesso antes apontado.

É óbvio que essa possibilidade histórica de recomposição de um pacto entre as elites no Brasil e que sustentou o governo FHC, o Plano Real e a contra-reforma nos anos 90, só foi possível com a derrota eleitoral e a situação defensiva das forças democráticopopulares no nível nacional, especialmente a partir de dois grandes pontos de inflexão: a derrota eleitoral de 1989, e o golpe fatal sobre os petroleiros, um segmento de ponta do movimento operário brasileiro, em sua histórica greve de 1995 (Rizek, 1998). Afinal, foram as forças do movimento operário e popular e aliados que asseguraram, numa luta árdua, algumas orientações progressistas

6 A lógica da capacidade para o trabalho preside a gestão dos benefícios assistenciais, o que vem sendo sinalizado seguidamente por Boschetti $(2001,2000$ e 1999). Um forte exemplo dessa lógica pode ser identificado no primeiro processo de revisão, previsto pela LOAS, do Benefício de Prestação Continuada, no qual foi utilizado um instrumental denominado "Acróstico Social", cuja aplicação rigorosa induzia nitidamente à exclusão de idosos e pessoas portadoras de deficiência do acesso ao benefício, considerando a capacidade para o trabalho. A revisão talvez explique a pouca ampliação do número de usuários nos últimos anos. O Conselho Federal de Serviço Social (CFESS), organização política dos assistentes sociais, manifestou-se em relação a este processo, denunciando as possibilidades de exclusão apontadas por meio do documento "A Revisão do BPC: a Posição do CFESS", o que certamente influiu nas modificações introduzidas neste instrumental quando da segunda revisão, bem como na decisão de que o processo não fosse implementado por leigos. A partir da nova revisão, os assistentes sociais passaram a fazer o trabalho. Cf. CFESS (abr. 2000 - www.cfess.org.br). 
na Constituição de 1988, com destaque para o capítulo da Ordem Social, que se desdobrou nas legislações complementares que vieram na sequência.

O projeto de seguridade social, e dentro dele, a novidade da inclusão da assistência social como política pública, fez parte dessas conquistas democráticas dos trabalhadores, na direção da reversão do drama crônico e do mito fundador, por meio de uma ampla e profunda reforma democrática do Estado a ser desencadeada, e que incluía o novo estatuto dos municípios e a revisão do pacto federativo no país, esta última também esquecida na era FHC, marcada por forte centralização de recursos e decisão política. No entanto, a transformação desse projeto em processo velo se deparando com aqueles obstáculos que situei ao longo dos anos 90, o que exigiu dos trabalhadores e militantes da área com ele comprometidos persistência cotidiana e paciência histórica muito grandes.

O que mudou do ponto de vista legal - e teve impactos sociais reais, que poderiam ser maiores, não fossem os obstáculos apontados - no campo da assistência social com a Constituição, a LOAS e demais instrumentos legais (NOB, decretos de instituição de Conselhos e Fundos)? Cabe fazer uma brevíssima síntese para poder delinear o perfil que se pode pensar para os trabalhadores no âmbito da implementação da assistência social no sentido constitucional e democrático.

Outro trabalho de Boschetti (2000), sintetiza bem a natureza e a profundidade do que se poderia caracterizar como uma arrojada arquitetura institucional e uma nova condição ético-politíca para a assistência social no Brasil. Segundo a autora, a LOAS significou o "fim da travessia do deserto", ao superar a compreensão corrente de dever moral de ajuda (de natureza humanitária e subjetiva, sujeita a possibilidades pessoais e políticas), passando-se a entendê-la como dever legal de garantia de benefícios e serviços sociais, ou seja, como direito assegurado pelo Estado. Em sendo direito, passa a existir obrigatoriedade legal para sua implementação e amparo legal para sua reclamação por parte dos cidadãos usuários. Como direito gratuito e não contributivo, o direito assistencial não se vincula a qualquer tipo de contribuição, e as entidades, mesmo privadas, que o viabilizam não podem auferir lucros. 
A LOAS definiu dois tipos de direitos: na forma de prestações monetárias continuadas e eventuais ${ }^{7}$ (pessoais e intransferíveis; condicionadas à comprovação de necessidade e categoriais); e na forma de serviços, programas e projetos, cuja natureza tende a ser mais coletiva, já que rompem com a perspectiva contratual imposta pela lógica da capacidade ou incapacidade para o trabalho. Ao lado disso, inovou-se muito em termos do controle social, com o processo de descentralização associado ao comando único das ações, na perspectiva de superar a fragmentação e a superposição das ações. Nessa direção, tem-se uma hierarquia de responsabilidades entre as esferas de governo ao lado da relação que Boschetti (2000) caracterizou criativamente como uma espécie de colaboração vigiada entre os poderes públicos e o mundo da filantropia, o qual permanece forte no campo assistencial. A perspectiva da LOAS foi a de estabelecer transparência nessa relação público-privado, tendo como horizonte estratégico a constituição de uma esfera pública (Raichellis, 1998).

Todos esses processos são discutidos e pactuados nos Conselhos de composição paritária entre governo e sociedade civil, cujo papel seria o de constituir-se numa arena de negociação e conflito, por meio da qual seria redimensionada a relação entre Estado e sociedade civil. Um terço da composição da representação da sociedade civil é dos trabalhadores da área. Portanto, esta é uma instância em que os trabalhadores têm um papel fundamental (Behring, 2001). Pela estrutura dos conselhos são aprovadas as medidas substantivas da assistência social: os planos (a política, no caso nacional) e as propostas de orçamento para os fundos. Estes, por fim, também são inovação em articulação com o controle social. Inovou-se na definição das fontes, bem como sua orientação pelos princípios da co-responsabilidade e da redistributividade.

\footnotetext{
Como já sinalizei, benefícios eventuais até hoje não estão regulamentados o que mostra a morosidade dos avanços na área. Se observamos o processo geral de sua regulamentação desde a Constituição, essa falta de centralidade da assistência social num país onde 44 milhões de pessoas passam fome (Fome Zero, 2001) e no qual há cerca de $20 \%$ de desemprego nas regiões metropolitanas segundo o DIEESE/SEADE, se evidencia de forma contundente. A LOAS foi aprovada cinco anos depois da Constituição; Conselho Nacional e Fundo passam a existir a partir de 1996. Uma Política Nacional e a Norma Operacional Básica foram aprovadas apenas em 1998 (Martins, 2001). Esta lentidão também expressou as prioridades do governo $\mathrm{FHC}$, que privilegiou - com prestígio e recursos - o Programa Comunidade Solidária em detrimento da política pública, fortalecendo assim o clientelismo e o primeiro-damismo. Com isso, a assistência social chegou a 2002 sem um comando único das ações, conforme a LOAS (Telles, 1998).
} 
Pois bem, aí estão as linhas gerais do projeto. Mas quando ele se colocou em movimento, em processo, em tempos de neoliberalismo, pôde-se observar os vários pontos de rigidez para que a LOAS se consolidasse, em especial o financiamento, sempre submetido à lógica fiscal, em detrimento das demandas constituídas pelas necessidades da população, e sempre menor que o orçamento do Comunidade Solidária ao longo da era FHC (Boschetti, 2001, Capítulo 2).

As experiências democrático-populares têm a obrigação política de enfrentar ao máximo estes pontos de rigidez - em todos os níveis de governo -, demonstrando seu compromisso, e se diferenciando de governos passados e atuais que desenvolveram e ainda desenvolvem práticas conservadoras na área da assistência social, a exemplo de seu deslavado uso político-eleitoral. Trata-se, portanto, de imprimir uma direção diferenciada, para que a nova condição ético-política apontada pela LOAS se realize, efetivando dessa maneira uma verdadeira reforma democrática, necessária frente às tradições político-econômicas herdadas, já referidas. No entanto, embora ainda que numa análise preliminar, observa-se que esta concepção da assistência social não foi plena e profundamente compreendida por partidos e governos de esquerda, que nem sempre tomaram para si a tarefa. Tal fato exigiu e continuará exigindo um grande esforço de discussão e convencimento, principalmente agora com a criação de um Ministério no governo Lula. Além disso, as restrições orçamentárias permanecerão fortes enquanto forem mantidas as amarras da macroeconomia do Real, que engessam a capacidade de investimento do setor público. Assim, numa nova correlação de forças - portanto, com possibilidades objetivas de avanço -, a luta vai continuar tendo em vista um efetivo Sistema Único da Assistência Social que amplie e ressignifique o atual Sistema Descentralizado e Participativo, conforme anuncia o Relatório do Setorial Nacional de Assistência Social do Partido dos Trabalhadores (2002).

\section{O perfil dos trabalhadores da Assistência Social: um esboço}

Bem, projeto e processo andam sobre as pernas de vários sujeitos e forças sociais: usuários, prestadoras públicas - que deveriam ter primazia - e privadas de serviços, legisladores, juristas, gestores, parlamentares e trabalhadores da área. A contribuição deste 
artigo, daqui para adiante, estará centrada no papel dos trabalhadores que, ao meu ver, têm uma grande importância que se localiza nos mecanismos de controle social e sua relação com a implementação do projeto da LOAS, que se insere de uma forma mais ampla numa perspectiva democrática de reforma do Estado, e, sobretudo, na relação com os usuários, ao pautarem sua intervenção profissional na direção da garantia de direitos, do que vou tratar em primeiro lugar. Vale dizer que, diferente da Saúde, que hoje tem sua NOB de Recursos Humanos e realiza conferências específicas sobre essa questão, a área da assistência social pouco avançou nesse sentido, o que provavelmente tem a ver com a dispersão institucional, fragmentação e superposição de ações, e falta de investimentos que configuraram historicamente esse campo e as dificuldades que este tem encontrado para sair da intenção e tornar-se gesto, diga-se, transformar-se efetivamente numa política. O esforço de capacitação da Secretaria de Estado da Assistência Sicial (SEAS), por meio de teleconferências, centrou-se na difusão de uma concepção de assistência social frontalmente contrária à LOAS.

$\mathrm{Na}$ verdade, ficou evidente ao preparar as palestras que deram origem a este artigo, que existe pouca produção acadêmica sobre a questão dos trabalhadores da assistência social, a não ser que façamos uma abordagem redutora, segundo a qual o trabalhador da assistência social é apenas o assistente social. Aqui irei falar de trabalhadores da assistência social de uma maneira geral, o que inclui as ricas reflexões e experiência destes, mas não se limita aos assistentes sociais, envolvendo outras profissões e trabalhadores de nível médio e fundamental. Uma nova condição ético-política da assistência social requisita uma nova mentalidade entre os trabalhadores e também entre os governantes/gestores.

Vejamos, então, o aspecto da relação com os usuários, e que remete ao novo perfil que se requer do trabalhador voltado para a construção do espaço público e do direito, segundo o projeto da LOAS. O governo FHC falava, na área da saúde, em humanização do atendimento do SUS, que parecia resumir-se ao simpático e atencioso tratamento dos usuários, sem sérias preocupações com as condições de acesso ao serviço/direito e com sua efetividade prática ou resultado. A idéia de humanização relacionava-se ainda menos com as condições de trabalho dos trabalhadores - que vão desde a existência dos meios básicos para a realização dos serviços - cuja inexistência desmoraliza qualquer perspectiva humanizadora e provoca imensos mal-estar e angústia entre os trabalhadores -, 
passando por uma política de capacitação dos recursos humanos para a compreensão ampla da política e de seu componente civilizatório e ético, até os salários e direitos trabalhistas. Embora, evidentemente, os usuários mereçam ser bem recebidos nas unidades de saúde, assistência social ou previdência, me parece que desvincular isso da efetividade prática do serviço - que depende do aporte de recursos, os quais vem sendo apropriados para outros fins, a exemplo do pagamento de encargos financeiros da União - e da valorização dos trabalhadores, é pura demagogia. Como aponta Vasconcelos (2000, p. 136), "o respeito e a humanização não se dão pela solidariedade humana, pela ajuda, pela pena, pelo tratamento dispensado, mas pelo direito de usufruir daquilo que a humanidade vem conquistando e produzindo ...".

O CFESS sugeriu um documento bem interessante sobre essa questão, que foi apresentado e enriquecido por uma Comissão designada pelo Conselho Nacional de Saúde, que, posteriormente, o aprovou em 2001. O documento foi considerado, é óbvio, abstrato pelos representantes do governo $\mathrm{FHC}$. Isto porque ele relacionou a humanização ao financiamento da política, às condições de trabalho e vida da população, bem como dos trabalhadores da saúde. Ou seja, situou a humanização historicamente e afastou-se da humanização como mero solidarismo. O documento, por sua vez, criticava o discurso de humanização de José Serra, à frente do Ministério da Saúde, este sim, como abstrato, já que não apontava claramente os meios de realizar a acessibilidade e a humanização, por meio de uma política de saúde com plena resolutividade. Esta reflexão na área da saúde me parece fundamental nesse momento, já que o documento reforça a responsabilidade e a atitude éticopolítica dos trabalhadores da área, mas situa o contexto real em que esta atitude se realiza ou não. Como a discussão que irei apontar é um tanto prescritiva, todo o tempo há que buscar a referência de que possíveis avanços relacionam-se à correlação de forças, ao contexto histórico: realizar a assistência como direito requer condições objetivas. Por outro lado, o debate da saúde oferece pistas para pensar o significado de humanização para a assistência social, que veio sofrendo restrições orçamentárias ainda maiores, é mais frágil institucionalmente e conta com poucos segmentos de trabalhadores e usuários organizados. A fiscalização dos serviços prestados nesse campo para idosos e pessoas portadoras de deficiência (Serviços de Ação Continuada), sobretudo da rede 
filantrópica que recebe o CEBAS, poderá revelar o quanto é importante esse debate para o campo assistencial.

Isto posto, é possível prosseguir, mas com uma advertência: estarei falando principalmente do setor estatal, cuja primazia está prevista em lei, no que se refere às políticas de seguridade. Mas, se compreendemos a rede assistencial privada como complementar à política e como parte de um Sistema Único, a atitude dos trabalhadores e de empregadores/gestores nesse âmbito deve pautar-se em princípios semelhantes, na intenção de construir um sistema público integrado e coerente.

Uma contribuição importante para pensar o perfil desse novo trabalhador voltado para a coisa pública, numa reforma democrática do Estado (e da sociedade) no Brasil pode ser encontrada em Nogueira (1998). Este autor sistematiza suas formulações em contraposição a duas tendências. Primeira, a do senso comum alimentado pela mídia e que formou uma opinião pública negativa sobre os trabalhadores dos serviços públicos, operação que fez parte da construção de um processo de deslegitimação dos serviços públicos e da organização sindical dos servidores, um componente central da contra-reforma do Estado dos anos 90, a qual objetivou 0 ajuste fiscal e as privatizações. ${ }^{8}$ Segunda, a do ceticismo e desânimo dos trabalhadores, que gerou e gera um clima de ausência de compromissos, de alheamento para com as questões substantivas e os dispositivos legais, ou de outro lado, uma atitude meramente corporativa em torno tão somente das condições de trabalho, ou seja, sem responsabilidade para com o público. Para Nogueira, não existe uma política de recursos humanos no Brasil que vise elevar os trabalhadores à condição de personagens ativos de uma reforma democrática do Estado.

Trilhar um caminho diferente, é delinear o perfil de um trabalhador sintonizado com as exigências de uma época onde o sólido se esfuma, onde a velocidade das transformações dificulta os momentos de síntese. Tudo isso ocorre simultaneamente ao espraiar ostensivo da desigualdade, da pobreza, do enfraquecimento do Estado e da política, a partir das reformas orientadas para o mercado.

8 Algumas infelizes declarações de membros do governo Lula a respeito dos servidores públicos têm sido divulgadas pela imprensa, especialmente no contexto do debate da reforma da previdência. Apesar disso, espera-se do novo governo uma relação democrática e respeitosa. Ainda é cedo para fazer prognósticos mais ou menos otimistas, em que pesem sinais não muito animadores. 
Um ambiente no qual um planejamento rígido e burocrático é incapaz de lidar com um sem-número de situações que se superpõem em tempo real. Assim, o perfil que se delineia para uma reforma democrática do Estado, da qual faz parte a assistência social como política pública de seguridade inserida nesse contexto, não depende tanto de tecnologias gerenciais e de sofisticados planos reformadores, mas de "pessoas capazes de operar na tênue fronteira entre técnica e política" (Nogueira, 1998, p. 187). Para tanto, sugere que se incorpore uma outra forma de pensar: recuperar e radicalizar as orientações totalizantes, históricas e dialéticas que permitem interpretar a multidimensionalidade das demandas dos usuários e das organizações/instituições e suas possibilidades de resposta. Assim, ele conclui que o trabalhador necessário hoje nesse ambiente, sobretudo nas instituições públicas,

"(...) precisa ser técnico e político, isto é, operar como um agente de atividades gerais que possui conhecimentos específicos, como um planejador que trabalha 'fora' dos escritórios, com os olhos no processo societal abrangente, em seus nexos contraditórios e explosivos; como um profissional cujo êxito depende de uma dinâmica que não é friamente controlável, mas é essencialmente política, e como tal, não se deixa isolar dos interesses e das paixões humanas (sonho dos tecnocratas...). Seu raio de ação está colado aos problemas da democracia, da representação e da participação" (Nogueira, 1998, p. 189).

Este trabalhador ${ }^{9}$ é um "difusor de estímulos favoráveis à democratização, à transparência governamental, à cidadania, à redefinição das relações entre governantes e governados, Estado e sociedade civil", e batiza-o de profissional da articulação, o qual teria as seguintes características:

"competente para negociar com atores mais desagregados e fragmentados, mais carentes e solicitantes, mais excluídos e mais cientes de seus direitos. E seu trabalho terá tanto mais relevo quanto mais colaborar para que se rompa categoricamente o hiato entre técnica e política, quanto mais desmontar a imagem da técnica como coisa neutra, autônoma, fatal, invencível, quanto mais compreender que as soluções por ele buscadas dependem de um devir coletivo complexo" (Nogueira, 1998, p. 190).

${ }^{9} \mathrm{E}$ aqui é possível afirmar que a proposta de formação profissional dos assistentes sociais, desde que passaram a assumir um projeto ético-político sintonizado com a radicalização da democracia, aqui compreendida como socialização da economia, da política e da cultura (Netto, 1999), está bem próxima a este perfil, ainda que existam práticas pouco condizentes com essa direção social apontada pelas Diretrizes Curriculares da ABEPSS (1996) e pelo Código de Ética da profissão. O processo de adesão e incorporação dessa direção estratégica, na verdade, passa por outras mediações e escolhas. Para uma problematização desta questão, ver lamamoto (2002). 
Trata-se de um profissional que integra as escolhas técnicas no circuito da decisão democrática. Os gestores sociais, de maneira ainda mais contundente, para Nogueira, são chamados a se converterem em lideranças, especialistas capacitados para pesquisar, negociar, aproximar pessoas e interesses, planejar, executar e avaliar. Devem ser competentes para pensar a crise, os movimentos da economia, da cultura e da política. Assim, não se trata de gerenciar, mas de tomar-se elemento ativo do governar, já que "os enlaces entre globalização, complexidade e questão social fizeram do governar uma operação difícil demais, impossível de ser enfrentada com recursos políticos e administrativos concebidos como coisas separadas" (Nogueira, 1998, p. 191). Esse novo gestor público da área social combina-se com "um Estado capaz de pensar estrategicamente, planejar, coordenar, focalizado no cidadão, competente para fomentar a cooperação e radicalmente público" ( $p$. 191).

As observações de Nogueira são extremamente importantes para pensar o perfil do trabalhador requerido pelo conceito democrático de seguridade social, traduzido na LOAS. Na relação com a implementação do projeto da LOAS e com os usuários, os trabalhadores - aí incluídos os assistentes sociais - podem contribuir com uma atuação voltada para o reforço de princípios ético-políticos democráticos e da coisa pública, numa atitude de permanente vigília em torno da viabilização do direito e dos processos decisórios democráticos.

No que se refere à relação com os usuários na perspectiva do direito e à construção de políticas radicalmente públicas de parte dos trabalhadores, a reflexão sobre a ética no serviço social brasileiro acrescenta outros elementos às sugestões de Nogueira. Sales (1999), no texto sobre a atitude ética dos que lidam com a questão social, do Curso à Distância para Assistentes Sociais (CFESS/ABEPSS/ UnB), ${ }^{10}$ lembra do papel da ética de elucidar ou agudizar o sentido das opções diante dos dilemas humanos. Nesse sentido, a ética tem o papel de educar os sentidos e orientar as escolhas na busca das melhores soluções e valores, num mundo sacudido por contradições. A agudização das expressões da questão social neste final de século, mais do que nunca para a autora, reivindica que a ética esteja

${ }^{10}$ Esta foi uma experiência de capacitação à distância que atingiu diretamente cerca de 1.600 profissionais de Serviço Social, em nível nacional, entre 1998 e 2001, coordenada pelas entidades nacionais da categoria numa parceria com a Universidade de Brasília. Um projeto com impactos importantes no trabalho e na vida desses profissionais, concebido na perspectiva democrática e pública aqui propugnada. 
imbricada ao exercício profissional dos que com elas lidam em seu cotidiano. A cotidianidade, no entanto, pressiona pelo fatalismo, 0 imediatismo, o senso-comum e o culto da ação pela ação, sendo um território eminentemente contraditório: propício à alienação e, ao mesmo tempo, e paradoxalmente, grávido das possibilidades do humano genérico, desde que se rompa com o senso comum, segundo apontam Brites e Sales (2000). ${ }^{11}$ Para que se desenvolva um trabalho com o estatuto de praxis - como atividade consciente e criadora - há que desenvolver plenamente a função intelectual, buscando compreender os fatores sociopolíticos, econômicos e culturais que obstruem o acesso à realização de aspirações humanas simples, mas ao mesmo tempo tornadas tão inacessíveis e complexas na sociedade capitalista, rompendo com o senso comum ou o voluntário bom-senso. A partir dessa preocupação, Sales faz uma observação importante que vale para o assistente social e também para todos os trabalhadores que lidam com essa "matéria vida, tão fina"(Caetano Veloso):

"A sociedade, na pessoa de cada usuário dos serviços sociais, espera, portanto, de tais profissionais uma firme e constante resolução de empreender e executar todas as iniciativas que julgue serem as melhores, porque a postura ética também requer efetividade $\mathrm{e}$ eficácia, visto que a intenção inócua não é nada"(Sales, 1999, p. 146).

E continua, sinalizando que, ao lado de uma atitude que busca a realização efetiva de valores, o sentido da ação profissional se insere no cenário de lutas e propostas coletivas da sociedade brasileira em prol de uma cultura pública democrática, com o que se aproxima do debate de Nogueira. Mas apesar dessa dimensão ou possibilidade coletiva, há uma unicidade na experiência ética que pressupõe que ninguém pode responder em nosso lugar, ou seja, há uma responsabilidade e um compromisso, uma adesão consciente e crítica (Brites e Sales, 2000, p. 70) no plano individual a determinados valores. No caso, as autoras estão falando dos princípios e valores que orientam o Código de Ética do Assistente

${ }^{11}$ Conferir o Caderno 2 do Projeto Ética em Movimento empreendido pelo CFESS (2000). Este é - a atual gestão do CFESS vem dando continuidade a esta idéia - um projeto de formação de agentes multiplicadores sobre ética, cuja tarefa é reproduzir os conteúdos dos cursos nos estados. Tais conteúdos vão desde uma discussão sobre ética em geral, passando pela ética profissional e finalizando com a operacionalidade dos Conselhos como tribunais de ética profissional. Os objetivos do projeto são melhorar os resultados das atividades-fim dos conselhos e, principalmente, difundir e dar concretude aos valores éticos da profissão - em sintonia com as forças democráticas na sociedade brasileira - no interior dos projetos de trabalhos dos profissionais, hoje, em sua maioria no setor público. 
Social: a democracia, a cidadania, a justiça social, a liberdade, o respeito à diferença, a recusa do preconceito, dentre outros. Porém tais valores poderiam ser extendidos ao Código de Ética do Servidor Público, por exemplo. Portanto, é fundamental àquele profissional da articulação, de que nos falava Nogueira, uma competência técnica e política, cujos parâmetros são uma perspectiva ética que possui uma dimensão coletiva e uma dimensão individual, já que o coletivo anda sobre as pernas das pessoas em carne e osso e que tomam decisões aqui e agora.

Atuar na perspectiva de uma radical e democrática reforma do Estado, que desenvolva políticas públicas sociais, no nosso caso, a política de assistência social, impõe exigências, aprofundando as já delineadas para o nosso profissional da articulação. Beatriz Paiva faz uma síntese do que seria desejável como característica dos assistentes sociais, sobretudo como gestores de políticas sociais. No entanto, sua reflexão, a meu ver, pode ser extensiva a outros profissionais de formação universitária, ainda que não exclusivamente, já que deve existir uma perspectiva de que o conjunto dos trabalhadores envolvidos num mesmo processo de trabalho tenha uma visão global do processo em que estão inseridos a partir, claro, de suas possibilidades de apreensão diferenciadas, evitando o trabalho alienado, com o que o compromisso ético-político tende a se consolidar:

"o domínio de múltiplos saberes, que vão desde as legislações sociais
correntes, numa atualização permanente das regulamentações e
modificações que se processam; a arguta capacidade de análise das
relações de poder e da conjuntura; passando pelas estratégias de
planejamento e administração; até a construção de diagnósticos sociais
e de indicadores que possam subsidiar a melhor definição das ações.
Tudo isso, além dos cuidados com o monitoramento, avaliação e
prestação de contas, medidas comuns a este espaço de atuação"
(Paiva, 2000, p. 84).

É evidente que este perfil exige uma agressiva política de capacitação, reciclagem e renovação dos recursos humanos nas várias esferas do Estado brasileiro, tendo em vista a quebra das resistências conservadoras à reforma democrática e seu sentido radicalmente público. A realização de concursos públicos com qualidade e transparência são uma condição para isso, bem como a articulação com as universidades públicas para a formulação de iniciativas consistentes - presenciais ou à distância - para uma requalificação em massa da força de trabalho da seguridade social. Tal política é impensável sem o aporte de recursos para o conjunto 
do processo: elaboração de material didático, contratação de professores e consultores, infra-estrutura da capacitação, computadores, dentre outros.

Para além desta dimensão da relação com os usuários e da gestão qualificada, um outro aspecto diz respeito ao papel dos trabalhadores na consolidação da assistência social como direito e deve ser tratado aqui. Se o profissional da articulação está preocupado com o circuito democrático, os espaços de controle social, a exemplo dos Conselhos, são fundamentais. Nesse sentido, este trabalhador - e aqui os assistentes sociais têm um papel de destaque, por sua contribuição política e acadêmica neste debate pode contribuir para qualificar a participação. Uma forma de fazêlo é assegurar uma presença substantiva, qualificada e combativa nesses espaços, nos quais insidiosamente persistem condutas (neo)clientelistas e (neo)corporativas. Outra, é colaborar para a qualificação dos demais segmentos, em especial o de usuários, como apontam Boska (2000, p. 109) e também Paiva (2000, p. 88), na consolidação da política de assistência social na perspectiva democrática aqui defendida.

Nesse sentido, a socialização das informações referentes aos direitos coloca-se como central para o fortalecimento dos usuários (Silva, 2000, p. 124), tanto individual quanto coletivamente. Vasconcelos (2000, p. 130) fala da absolutamente necessária disponibilidade dos assistentes sociais para os segmentos populares - o que, a partir da particularidade dos demais segmentos de trabalhadores, deve orientá-los também - tendo em vista o fortalecimento das condições de participação destes na política pública. Nessa direção, aponta a prioridade para o trabalho com grupos e o fortalecimento da dimensão coletiva. Outro aspecto importante e que envolve a dimensão ética é a relação criteriosa e transparente com os recursos públicos, que se impõe aos gestores/ trabalhadores.

\section{Breve conclusão}

Este é um debate ainda em aberto e a intenção aqui é apenas oferecer pistas, considerando as possibilidades desta nova situação nacional, cuja direção política e intelectual e moral está em disputa. Procurei apontar, em síntese, que os trabalhadores da assistência social, ao aderirem à perspectiva técnica, política e ética aqui sugerida como um desdobramento da LOAS, podem atuar em várias 
dimensões, para a consolidação desta como política de seguridade social e parte de uma reforma democrática: no controle social, assegurando a qualidade da participação da sua representação e das demais; no trato dos recursos públicos; numa relação democrática e efetivamente humanizada com os usuários; dentre os múltiplos aspectos que envolvem a política. Uma dimensão não desenvolvida aqui é a da produção de planos consistentes do ponto de vista de sua fundamentação e de serem técnica e politicamente executáveis, para o qual os trabalhadores também podem e devem atentar. Os trabalhadores são, portanto, imprescindíveis e estratégicos na consolidação da política de assistência social, dentro de uma reforma democrática do Estado, tal como preconizada pela Constituição de 88, no seu conceito de seguridade social, e pela LOAS. Existiram embriões dessa perspectiva nas experiências democrático populares, a exemplo de Belo Horizonte, onde há, inclusive, uma minuta de proposta de Norma Operacional Básica de Recursos Humanos. No entanto, a possibilidade histórica desse profissional da articulação vincula-se à combinação entre a valorização dos trabalhadores, com melhores condições de vida e trabalho, e o redírecionamento das políticas públicas, particularmente a de assistência social, reduzida nos anos FHC a ações compensatórias e focalizadas, muitas vezes implementadas a partir de ações alienadas, reiterativas, repetitivas... enfim, cotidianas... bem distantes da idéia de praxis que orienta o perfil aqui delineado, que atua na perspectiva do direito; ou pior, por leigos voluntários sem coordenação técnica consistente. Agora a expectativa é a de que haja maior ousadia e coragem para assumir a assistência social na concepção constitucional.

\section{Bibliografia}

BEHRING, Elaine R. As reformas na Política de Assistência Social: da benemerência ao Direito Social, da solidariedade às parcerias entre o público e o privado. Universidade e Sociedade, Brasília, n. 22, nov. 2000.

Política Social no Capitalismo Tardio. 2. ed. SP, Cortez, 2002a.

Acontra-reforma do Estado no Brasil. Rio de Janeiro, 2002b.Tese (Doutorado em Serviço Social) - UFRJ.

. Os Conselhos de Assistência Social e a construção da Democracia. Cadernos ABONG, Política de Assistência Social: uma trajetória de avanços e desafios, São Paulo, n. 30 nov. 2001. 
BOSCHETTI, Ivanete. Assistência Social no Brasil: um direito entre a originalidade e o conservadorismo. Brasília, GESST/DSS/UnB, 2001.

. As políticas brasileiras de Seguridade Social: Assistência Social. In: CAPACITAÇÃO em Serviço Social e Política Social. Módulo 3. Brasília, CFESS/ABEPSS/CEAD-UnB, 2000.

A perspectiva da Assistência Social nos governos populares. 1999. (Mimeogr).

BOSKA, Helder. Serviço Social: das tradicionais formas de regulação sociopolíticaao redimensionamento das suas funções sociais. In: CAPACITAÇÃO em Serviço Social e Política Social. Módulo 4. Brasília, CFESS/ABEPSS/ CEAD-UnB, 2000.

BRITES, Cristina Maria; SALES, Mione Apolinário. Ética e praxis profissional. Brasília, Projeto Ética em Movimento/CFESS, 2000.

CFESS. A revisão do BPC: a posição do CFESS. Brasília: CFESS, abril de 2000.

As recentes denúncias sobre o CNAS: a posição do CFESS. Brasília, novembro de 2001.

. Carta de Maceió. Maceió, CFESS, setembro de 2000.

CHAUÍ, Marilena. Brasil: mito fundador e sociedade autoritária. São Paulo: Fundação Perseu Abramo, 2000.

COUTINHO, Carlos Nelson. Uma via 'não-clássica' para o Capitalismo. In: D'INCAO, Maria Angela (Org.). História e ideal: ensaios sobre Caio Prado Júnior. São Paulo: UNESP, Brasiliense, 1989.

DURIGUETTO, Maria Lúcia. Democracia: polêmicas, confrontos e direcionamentos. 2003. Tese (Doutorado, em Serviço Social)-ESS/UFRJ.

FERNANDES, Florestan. A revolução burguesa no Brasil: ensaio de interpretação sociológica. 3. ed. Rio de Janeiro: Ed. Guanabara, 1987.

GUSMÃO, Rute. A ideologia da solidariedade. 1998. Monografia do Curso de Especialização em Políticas Sociais, FSS/UERJ. (Mimeogr).

IAMAMOTO, Marilda. Projeto profissional, espaços ocupacionais e trabalho do Assistente Social na atualidade. In: CFESS. Atribuições privativas do(a) assistente social em questão. Brasília: CFESS, 2002.

INESC. Informativo Observatore, Brasília, v. 3, n. 31, maio 2001.

MARTINS, Valdete de B. Implantação da Política Pública de Assistência Social: desafios sob a ótica do gestor. Cadernos ABONG, Política de Assistência Social: uma trajetória de avanços e desafios, São Paulo, n. 30, nov. 2001.

MARX, Karl. O 18 de Brumário de Luís Bonaparte. Portugal: Ed. Estampa, 1976. 
MATTOSO, Jorge. O Brasil desempregado: como foram destruídos mais de 3 milhões de empregos nos anos 90. São Paulo: Fundação Perseu Abramo, 1999.

NETTO, José Paulo. A construção do pojeto ético-político do Serviço Social frente à crise contemporânea. In: CAPACITACÃO em Serviço Social e Política Social. Brasília: CFESS/ABEPSS/CEAD-UnB, 1999.

NOGUEIRA, Marco Aurélio. As possibilidades da política. São Paulo: Paz e Terra, 1998. In: CAPACITACÃO em Serviço Social e Política Social. Módulo 4. Brasília: CFESS/ABEPSS/ CEAD-UnB, 2000.

PAIVA, Beatriz. Reflexões sobre pesquisa e processos de formulação e gestão. In: CAPACITAÇÃO em Serviço Social e Política Social. Módulo 4. Brasília: CFESS/ABEPSS/ CEAD-UnB, 2000.

RAICHELIS, Raquel. Esfera pública e Conselhos de Assistência Social: caminhos da construção democrática. São Paulo, Cortez, 1998.

RIZEK, Cibele Saliba. A greve dos petroleiros. Revista Praga: Estudos Marxistas, São Paulo, n. 6, 1998.

SALES, Mione A. questão social e defesa de direitos no horizonte da ética profissional: In: CAPACITAÇÃO em Serviço Social e Política Social. Módulo 3. Brasília: CFESS/ABEPSS/CEAD-UnB, 1999.

SCHWARZ, Roberto. Ao vencedoras batatas: forma literária e processo social nos inícios do romance brasileiro. São Paulo: Duas Cidades, 1977.

SILVA, Maria Lúcia Lopes da. Um novo fazer profissional. In: CAPACITAÇÃO em Serviço Social e Política Social. Módulo 4. Brasília: CFESS/ABEPSS/ CEAD-UnB, 2000.

TELLES, Vera. A 'nova questão social' brasileira. Revista Praga: Estudos Marxistas, São Paulo, n. 6, 1998.

VASCONCELOS, Ana Maria. O trabalho do assistente social e o projeto hegemônico no debate profissional. In: CAPACITAÇÃO em Serviço Social e Política Social. Módulo 4. Brasília: CFESS/ABEPSS/CEAD-UnB, 2000.

\section{Documentos Oficiais}

Documento Efetivação da Acessibilidade e Humanização da Atenção à Saúde no SUS. Conselho Nacional de Saúde, 2000.

Plano Diretor da Reforma do Estado. Ministério da Administração e da Reforma do Estado. Brasília, 1995.

Projeto Fome Zero. Documento Síntese, 3ㄹ Versão. Instituto da Cidadania, outubro de 2001.

Relatório do Setorial Nacional de Assistência Social do Partido dos Trabalhadores. Brasília, dezembro de 2002. 